慶應義塾大学学術情報リポジトリ

Keio Associated Repository of Academic resouces

\begin{tabular}{|c|l|}
\hline Title & TARIFFS AND THE TRANSFER PROBLEM \\
\hline Sub Title & \\
\hline Author & 大山, 道廣(OHYAMA, MICHIHIRO) \\
\hline Publisher & Keio Economic Society, Keio University \\
\hline Publication year & 1974 \\
\hline Jtitle & Keio economic studies Vol.11, No.1 (1974. ) ,p.29-45 \\
\hline JaLC DOI & \\
\hline Abstract & \\
\hline Notes & \multicolumn{1}{|c|}{ Journal Article } \\
\hline Genre & $\begin{array}{l}\text { https://koara.lib.keio.ac.jp/xoonips/modules/xoonips/detail.php?koara_id=AA00260492-1974000 } \\
1-0029\end{array}$ \\
\hline URL &
\end{tabular}

慶應義塾大学学術情報リポジトリ(KOARA)に掲載されているコンテンツの著作権は、それぞれの著作者、学会または出版社/発行者に帰属し、その権利は著作権法によって 保護されています。引用にあたっては、著作権法を遵守してご利用ください。

The copyrights of content available on the KeiO Associated Repository of Academic resources (KOARA) belong to the respective authors, academic societies, or publishers/issuers, and these rights are protected by the Japanese Copyright Act. When quoting the content, please follow the Japanese copyright act. 


\title{
TARIFFS AND THE TRANSFER PROBLEM
}

\author{
MichIHIRO OHYAMA
}

\section{INTRODUCTION}

The transfer problem has attracted a great deal of attention in the literature of international trade theory since the famous controversy between Keynes and Ohlin on the late 1920's. Practically, the international transfer of purchasing power is widely observed in various guises of private remittance, reparation, economic aid, etc. Theoretically, it poses an interesting question concerning the real income effect of income transfers between countries. This question lurks also in the analysis of currency devaluation often conceived as an attempt to affect the international terms of trade in order to create a trade surplus. Discussing the German reparation problem, Keynes (1929) held the position that the expenditure of the German people will be reduced, not only by the amount of reparation, but also by a decrease in their gold-rate of earnings. As Ohlin (1929) pointed out quickly, however, Keynes thereby failed to pursue the logic of his own argument: "if $£ 1$ is taken from you and given to me and I choose to increase my consumption of precisely the same goods as those of which you are compelled to diminish yours, there is no transfer problem."' Later analysis, notably Samuelson (1952, 1954) and Johnson (1956), elucidated the implications of this logic in the context of a two-country, two-commodity model of trade. They showed that the direction of change in the terms of trade depends crucially upon the relative magnitude of the marginal propensities to consume between the two countries. There is, however, no presumption about this relative magnitude under free trade with no trade impediments.

As Samuelson argued quite convincingly, we need either to remold the basic structure of the model or to introduce trade impediments into the picture if we are to give credit to the orthodox view held by Keynes and other classical economists on the "additional" burden of a transfer. In this paper, we intend to give a microscopic study of the transfer problem in relation to tariffs, one of the typical trade impediments. Needless to say, tariffs create a divergence between the internal and external prices thereby affecting the volume of trade and giving rise to tariff revenue. It is because of this obvious property of tariffs that we cannot disregard its special bearing on the transfer problem. Aside from Samuelson's celebrated studies, however, there seems to be little literature exploring the implications of this fundamental recognition.

The next section will provide the analytical groundwork for our inquiry. In

${ }^{1}$ See Keynes (1929), p. 2. 
Section III, we shall investigate the effect of an international transfer on the terms of trade and the real incomes. It will be emphasized that the change in a country's tariff revenue resulting from a transfer constitutes a genuine real income effect in addition to the change in the initial income and the terms of trade. Section IV will be devoted to the study of the anomalous case that the transferor becomes better-off or the transferee gets impoverished as a result of transfer. Finally, in Section V, we shall consider the neglected issue of tied transfer, whcih may be regarded as a further aspect of the relevance of tariffs to the transfer problem.

\section{THE MODEL}

In order to analyze the transfer problem in the presence of tariffs, we have to modify slightly the standard model of tariffs. As usual, let there be two countries, home and foreign, and two commodities, 1 and 2. Each country is assumed to produce and consume both of the two commodities under perfectly competitive conditions. There are no domestic distortions such as factor rewards differentials between industries, or external economies. In each country, the domestic supply of productive resources is fixed in quality as well as in quantity. The home country is supposed to export commodity 1 , and the foreign country commodity 2 in a trade equilibrium. The home country imposes a tariff on the import of commodity 2 , and the foreign country on the import of commodity 1 . This produces a cleavage between the home prices $p_{i}(i=1,2)$ and the foreign prices $p_{i}^{*}(i=1,2)^{2}$ :

$$
\begin{aligned}
& p_{1}^{*}=p_{1} t^{*}=p_{1}\left(1+\tau^{*}\right) ; \\
& p_{2}=p_{2}^{*} t=p_{2}^{*}(1+\tau)
\end{aligned}
$$

where $t$ (resp. $t^{*}$ ) represents unity plus the home (resp. foreign) ad valorem rate $\tau$ (resp. $\tau^{*}$ ). The tariff proceeds are assumed to be given away to the public in the form of lump-sum subsidies.

This setting is merely a reproduction of the standard model of tariffs. In addition, however, we assume that the home country pays an indemnity $b(>0)$ fixed in terms of the common unit of account. The home country raises this amount by lump-sum taxes, and the foreign country uses it as lump-sum subsidies. Under these conditions, the consumers' budget constraint implies

$$
\begin{aligned}
& p_{1} e_{1}+p_{2} e_{2}=(t-1) p_{2}^{*} e_{2}-b ; \\
& p_{1}^{*} e_{1}^{*}+p_{2}^{*} e_{2}^{*}=\left(t^{*}-1\right) p_{1} e_{1}^{*}+b
\end{aligned}
$$

where $e_{i}$ (resp. $e_{i}^{*}$ ) denotes the home (resp. foreign) excess demand for commodity $i$. In other words, the excess demand values in domestic prices sum up to the net value of lump-sum subsidies given to the public in each country. Note that the excess demand $e_{i}$ is the difference between the demand $x_{i}$ and the supply $y_{i}$, or

2 We assume that the unit of home currency is adjusted such that the exchange rate is euqal to unity. Thus, the unit of account is common between countries. 
Similarly,

$$
e_{i}=x_{i}-y_{i}
$$

$$
(i=1,2) \text {. }
$$

$$
e_{i}^{*}=x_{i}^{*}-y_{i}^{*} \quad(i=1,2) .
$$

We assume that the demand is a function of internal prices and the country's real income, and that the supply is a function of internal prices. But a uniform doubling of accounting prices should not affect the behaviour of rational economic agents. For this reason, we may set the home price of commodity 1 at a certain fixed level. ${ }^{3} \quad$ Define

$$
\begin{aligned}
& p=\frac{p_{2}}{p_{1}} \\
& p^{*}=\frac{p_{2}^{*}}{p_{1}^{*}} \\
& \pi=\frac{p_{2}^{*}}{p_{1}}
\end{aligned}
$$

Then, we may write

$$
\begin{array}{lr}
e_{i}=e_{i}(p, u)=x_{i}(p, u)-y_{i}(p) & (i=1,2) ; \\
e_{i}^{*}=e_{i}^{*}\left(p^{*}, u^{*}\right)=x_{i}^{*}\left(p^{*}, y^{*}\right)-y_{i}^{*}\left(p^{*}\right) & (i=1,2)
\end{array}
$$

where $u$ (resp. $u^{*}$ ) denotes the home (resp. foreign) country's real income. We can interpret $\pi$ in (9) as the international terms of trade. Following the convention in the literature, we say that if $\pi$ increases (resp. decreases), the terms of trade deteriorates (resp. improves) from the home country's viewpoint.

An international trade equilibrium obtains if and only if the home country achieves the balance of trade surplus by the amount of the transfer payment when evaluated in international prices, i.e.

$$
p_{1} e_{1}^{*}-p_{2}^{*} e_{2}-b=0
$$

where

$$
e_{1}^{*}>0 ; \quad e_{2}>0 \text {. }
$$

For the prupose of comparative statics, it is necessary to rewrite the system described above in variational form. We assume that there is no transfer payment in the initial equilibrium, or $b=0$. This assumption is usually made to avoid unnecessary complication of the variational system. Let us express real income changes by

$$
\begin{aligned}
d u & =p_{1} d x_{1}+p_{2} d x_{2} ; \\
d u^{*} & =p_{1}^{*} d x_{1}^{*}+p_{2}^{*} d x_{2}^{*} .
\end{aligned}
$$

This formula gives us the Laspeyres index of real income changes. But note that its sign also agrees with the sign of the Paache index for a sufficiently small

${ }^{3}$ This implies the constancy of the foreign prices of commodity 1 under the given exchange rate and the given rate of tariffs. 
variation. ${ }^{4}$ To ease notation, let a circumflex $\left({ }^{\wedge}\right)$ indicate the relative change in a variable. For example, $\hat{t}$ denotes $d t / t$ and $\hat{p}$ denotes $d p / p$. We first totally differentiate the home excess demand function (10) for commodity 2 . Rearranging terms in view of (2), (7) and (9), we obtain

$$
\hat{e}_{2}=-\bar{\eta}_{2} \hat{\pi}-\bar{\eta}_{2} \hat{t}+m_{2}\left(\frac{1}{p_{2} e_{2}}\right) d u
$$

where

$$
\tilde{\eta}_{2}=-\frac{p}{e_{2}} \frac{\partial e_{2}}{\partial p} ; \quad m_{2}=p_{2} \frac{\partial x_{2}}{\partial u}
$$

The coefficient $\dot{\eta}_{2}$ of $\hat{\pi}$ and $\hat{t}$ is the "income compensated" elasticity of the home country's import demand, and the coefficient $m_{2}$ the home country's marginal propensity to consume the import commodity. From (1), (8), (9) and (11), we similarly get

$$
\hat{e}_{1}^{*}=\bar{\eta}_{1}^{*} \hat{\pi}-\bar{\eta}_{1}^{*} t^{*}+m_{1}^{*}\left(\frac{1}{p_{1}^{*} e_{1}^{*}}\right) d u^{*}
$$

where

$$
\bar{\eta}_{1}^{*}=\frac{p^{*}}{e_{1}^{*}} \frac{\partial e_{1}^{*}}{\partial p^{*}} ; \quad m_{1}^{*}=p_{1}^{*} \frac{\partial x_{1}^{*}}{\partial u^{*}} .
$$

We can interpret $\eta^{*}$ and $m^{*}$ as above except that they now pertain to the foreign country rather than to the home country. In order to rewrite (15) and (16), we need to obtain appropriate expressions for $d u$ and $d u^{*}$. For the home country, differentiate totally the budget constraint (3) taking notice of (5) and (10). Then, we can rewrite the result in the light of definitions (2), (7), (9) and (13) as follows:

$$
d u=-p_{2}^{*} e_{2} \hat{\pi}-d b+(t-1) p_{2}^{*} e_{2} \hat{e}_{2} .
$$

Here, the first term on the right hand side represents the terms of trade effect of the variation on the home country's real income. The second term stands for the direct effect of a transfer payment, and the last term the effect of a change in tariff revenue. Clearly, an increase in imports gives rise to an increase in tariff revenue under positive tariffs and an increase in subsidy expenditure under negative tariffs. In general, it is in the presence of some wedge between internal and external prices that this last effect appears reflecting some "arbitrage" loss or benefit for the country. For the foreign country we similarly obtain

$$
d u^{*}=p_{2}^{*} e_{2} \hat{\pi}+d b+\left(t^{*}-1\right) p_{1} e_{1}^{*} \hat{e}_{1}^{*}
$$

Now substitute (17) into (15) and collect terms. We get

$$
\hat{e}_{2}=-\varepsilon_{2} \hat{\pi}-\bar{\varepsilon}_{2} \hat{t}-\left(\frac{1}{p_{2}^{*} e_{2}}\right) \mu_{2} d b
$$

where

$$
\varepsilon_{2}=\frac{t}{t-m_{2}(t-1)}\left(\bar{\eta}_{2}+\frac{m_{2}}{t}\right)
$$

\footnotetext{
4 For this definition of real income changes, see also the discussion in Jones (1969).
} 


$$
\begin{aligned}
\bar{\varepsilon}_{2} & =\frac{t \bar{\eta}_{2}}{t-m_{2}(t-1)} \\
\mu_{2} & =\frac{m_{2}}{t-m_{2}(t-1)} .
\end{aligned}
$$

The symbol $\varepsilon_{2}$ (resp. $\bar{\varepsilon}_{2}$ ) signifies the (resp. "compensated") elasticity of the home country's offer curve. In a similar fashion, equation (16), together with (20), yields

$$
\hat{e}_{1}^{*}=\varepsilon_{1}^{*} \hat{\pi}-\tilde{\varepsilon}_{1}^{*} \hat{t}^{*}+\left(\frac{1}{p_{1} e_{1}^{*}}\right) \mu_{1}^{*} d b
$$

where

$$
\begin{aligned}
\varepsilon_{1}^{*} & =\frac{t^{*}}{t^{*}-m_{1}^{*}\left(t^{*}-1\right)}\left(\bar{\eta}^{*}+\frac{m_{1}^{*}}{t^{*}}\right) ; \\
\bar{\varepsilon}_{1}^{*} & =\frac{t^{*} \bar{\eta}_{1}^{*}}{t^{*}-m_{1}^{*}\left(t^{*}-1\right)} ; \\
\mu_{1}^{*} & =\frac{m_{1}^{*}}{t^{*}-m_{1}^{*}\left(t^{*}-1\right)} .
\end{aligned}
$$

The equilibrium condition (12) is shown in variational form as

$$
p_{2}^{*} e_{2}\left(\hat{e}_{2}-\hat{e}_{1}^{*}\right)+p_{2}^{*} e_{2} \hat{\pi}+d b=0 .
$$

From (21), (22) and (23), we obtain

$$
\hat{\pi}=\frac{1}{\Delta}\left\{\left(\bar{\varepsilon}_{1}^{*} \hat{t}^{*}-\bar{\varepsilon}_{2} \hat{t}\right)+\left(\frac{1}{p_{2}^{*} e_{2}}\right)\left(1-\mu_{1}^{*}-\mu_{2}\right) d b\right\}
$$

where

$$
\Delta=\varepsilon_{1}^{*}+\varepsilon_{2}-1 \text {. }
$$

Note that by the stability condition the generalized Marshall-Lerner expression $\Delta$ is positive.

The groundwork is now complete. We shall proceed to examine the problems posed earlier in this paper.

\section{THE EFFECT OF TRANSFER UNDER TARIFFS}

There is no ambiguity about the direct effect of a transfer payment. The past literature is primarily concerned with the delicate terms of trade effect. If a transfer results in a deterioration of the paying country's terms of trade under free trade, it means an additional loss of the latter's real income, and an extra gain for the receiving country. The so-called orthodox view suggests that this will in all probability be indeed the case. After examining the related literature exhaustively, Samuelson $(1952,1954)$ concludes that, in the absence of trade impediments such as tariffs and transport costs, the orthodox presumption turns out to fall completely to the side. In the tariff case, however, he shows by the technique of a box diagram that a transfer will tend to affect the terms of trade in favor of the receiving country when preferences are identical between the countries and representable by a set of homothetic indifference curves. We shall begin 
by examining this result in greater detail.

In order to focus upon the pure effect of an untied transfer let us assume in this section that the tariffs are invariable, viz.

$$
\hat{t}=0 ; \quad \hat{t}^{*}=0 .
$$

Then, from (24) we immediately get

$$
\hat{\pi}=\frac{1}{p_{2}^{*} e_{2} \Delta}\left(1-\mu_{1}^{*}-\mu_{2}\right) d b
$$

Since the home country imports commodity $2, e_{2}$ is positive. As noted above, the stability condition requires that $\Delta$ be positive. Hence,

$$
\hat{\pi} 0 \text { according as } \mu_{1}^{*}+\mu_{2}
$$

For simplicity, suppose that $t^{*}=1$, or the foreign country imposes no tariffs. Then, the orthodox view holds true if and only if

$$
m_{1}^{*}+\frac{m_{2}}{t-m_{2}(t-1)}<1 .
$$

in view of (26) and the definition of $\mu_{1}^{*}$ and $\mu_{2}$. Note that if the home country imposes no tariffs as well, then (27) reduces to the familair agnostic condition for the orthodoxy. We can state

Proposition 1. Suppose all commodities are normal in social consumption, or $0<m_{1}^{*}, m_{2}<1$. Then, the higher the rate of tariffs, the stronger is the presumption that a transfer payment from the home to the foreign country will shift the terms of trade against the former. For given values of $m_{1}^{*}$ and $m_{2}$, there is a critical rate of tariffs

$$
\bar{\tau}=\frac{m_{1}^{*}+m_{2}-1}{\left(1-m_{1}^{*}\right)\left(1-m_{2}\right)}
$$

such that the presumption holds if and only if $\tau>\bar{\tau}$.

The proof is straightforward. The critical rate is of course negative if $m_{1}^{*}+m_{\varepsilon}$ $<1$.

Corollary (Samuelson (1954)). If preferences are representable by a set of homothetic indifference curves with identical taste between the two countries, the orthodox view is valid under any positive tariffs.

In such a case, $m_{1}^{*}$ and $m_{2}$ add up to unity so that the critical rate of tariffs given by (28) becomes zero.

The basic relationship (25) can be interpreted as follows. Suppose for the moment that the terms of trade are unchanged in the face of the payment $d b$. This means that nowhere does a price change take place, and only income effects are at work. In the home country, the value of imports declines by $\left(m_{2} / t\right) d b$ in the first round. ${ }^{5}$ But this immediately causes a reduction in the tariff revenue by

${ }^{5}$ The value of imports (measured in international price) is given by $p_{2}{ }^{*} e_{2}$. Since

$$
m_{2}=\frac{\partial\left(p_{2} e_{2}\right)}{\partial b}=t \frac{\partial\left(p_{2}^{*} e_{2}\right)}{\partial b} \text {, we find } d\left(p_{2}^{*} e_{2}\right)=\left(\frac{m_{2}}{t}\right) d b \text {. }
$$


$(t-1)\left(m_{2} / t\right) d b$. So the "multiplier" process will go on, with each new round decreasing the value of imports by $(t-1)\left(m_{2} / t\right)$ of the previous round reduction. If $(t-1)\left(m_{2} / t\right)<1$, the upshot will be the total contraction of the import value by $m_{2} /\left(t-m_{2}(t-1)\right) d b$ or $\mu_{2} d b$. Similarly, in the absence of price changes, there will be in the foreign country the total expansion of the import value by $\mu_{1}^{*} d b$ at the termination of its tariff-import multiplier process. Now, the value $\left(\mu_{1}^{*}+\mu_{2}\right) d b$ represents the net trade surplus accruing to the home country under our supposition. If $\left(\mu_{1}^{*}+\mu_{2}\right) d b<d b$, there will be a deficit in the home country's balance of payments. To remove the deficit, the terms of trade must eventually deteriorate against the home country in a stable market. On the contrary, if $\left(\mu_{1}^{*}+\mu_{2}\right) d b>d b$, the home country's terms of trade must eventually improve.

In the present setting, more interesting than the terms of trade effect per se is the ultimate change in real incomes consequent upon an international transfer. As we shall see in a moment, there is under tariffs a further impact on the real incomes through import contraction or expansion. To capture this point in precise terms, we substitute (21) and (25) into (17), and (22) and (25) into (20). After some manipulations, we obtain

$$
\begin{aligned}
& d u=-\frac{1}{\Delta}\left\{\bar{\varepsilon}_{1}^{*}+\bar{\varepsilon}_{2}+(t-1)\left[\mu_{2} \bar{\varepsilon}_{1}^{*}+\left(1-\mu_{1}^{*}\right) \bar{\varepsilon}_{2}\right]\right\} d b \\
& d u^{*}=\frac{1}{\Delta}\left\{\bar{\varepsilon}_{1}^{*}+\bar{\varepsilon}_{2}+\left(t^{*}-1\right)\left[\left(1-\mu_{2}\right) \bar{\varepsilon}_{1}^{*}+\mu_{1}^{*} \bar{\varepsilon}_{2}\right]\right\} d b .
\end{aligned}
$$

If free trade prevails, or $t=t^{*}=1$, these simplify to

$$
\begin{aligned}
& d u=-\frac{1}{\Delta}\left(\bar{\eta}_{1}^{*}+\bar{\eta}_{2}\right) d b ; \\
& d u^{*}=1 \frac{1}{\Delta}\left(\bar{\eta}_{1}^{*}+\tilde{\eta}_{2}\right) d b .
\end{aligned}
$$

The usual assumption is that the "income compensated" elasticities of import demand are positive, or

$$
\bar{\eta}_{1}^{*}>0 ; \quad \bar{\eta}_{2}>0 .
$$

Thus, equation $\left(29^{\prime}\right)$ and $\left(30^{\prime}\right)$ confirm the familiar proposition that under free trade the home country (the transferor) is bound to become worse-off, and the foreign country (the transferee) better-off as a result of transfer.

In the presence of tariffs, we need to reconsider the simple free-trade result. As is clear from (29) and (30), a transfer under tariffs tends to exert a tertiary effect on the home and foreign real incomes in addition to the obvious primary effect and the terms of trade effect. As we have indicated, this tertiary effect is nothing but the change in each country's tariff revenue resulting from the transfer. It is, therefore, rather surprising that it has escaped closer attention in the controversies on the transfer problem. In each of equations (29) and (30), the third term on the right-hand side gives a compressed expression to the tertiary 
36

MICHIHIRO OHYAMA

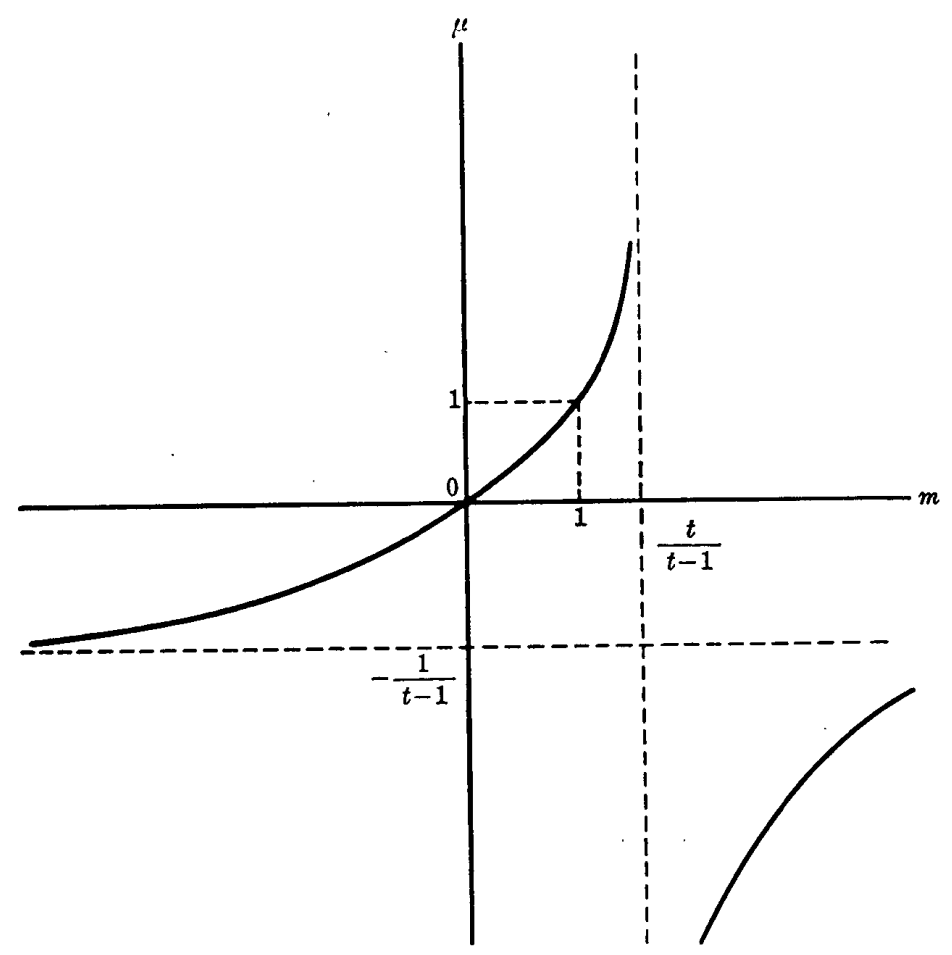

Fig. 1-i. $\quad t>1$

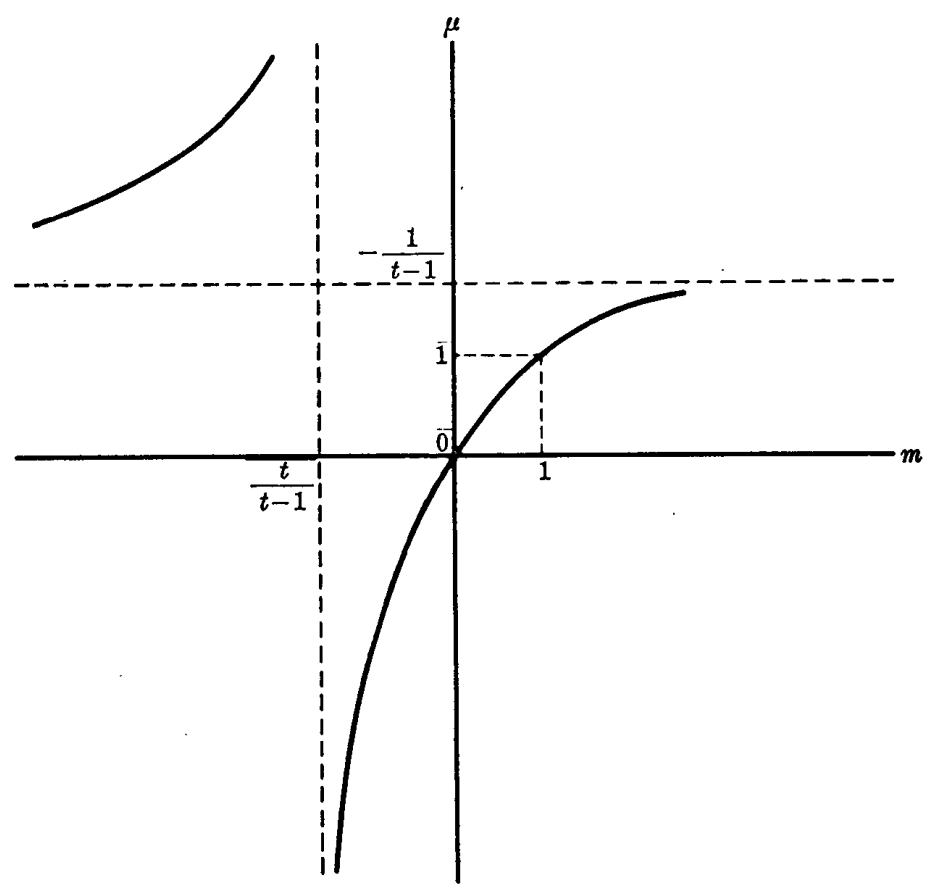

Fig. 1-ii. $0<t<1$ 
effect of transfer. To study its implications, we muts keep in mind the exact relationship between the pair of parameters, $\mu_{2}$ and $m_{2}$, or $\mu_{1}^{*}$ and $m_{1}^{*}$. Figures 1-i and 1-ii are introduced to visualize this relationship for positive and negative rates of tariffs. Observe

$$
\begin{aligned}
& 0<\mu_{2}<1 \quad \text { if and only if } 0<m_{2}<1 ; \\
& 0<\mu_{1}^{*}<1 \text { if and only if } 0<m_{1}^{*}<1 .
\end{aligned}
$$

On the other hand, from the defiuition of $\bar{\varepsilon}_{2}$ and $\bar{\varepsilon}_{1}^{*}$,

$$
\begin{array}{ll}
\bar{\varepsilon}_{2}>0 & \text { if } \quad 0<m_{2}<1 \\
\bar{\varepsilon}_{1}>0 & \text { if } \quad 0<m_{1}^{*}<1 .
\end{array}
$$

This, together with (29) and (30), establishes

Proposition 2. Suppose all commodities are normal. Then, under positive tariffs, the tertiary effect of transfer is definitely negative for the paying country, and definitely positive for the receiving country. Under negative tariffs (that is, import subsidies), it is definitely positive for the paying country, and definitely negative for the receiving country.

Note that the tertiary effect for each country does not directly depend on the other country's tariffs.

The results of Propositions 1 and 2 lead us naturally to the suspicion that the transferor will suffer from an additional burden, and the transferee to enjoy an extra benefit under the conditions of heavy tariffs and superior commodities. In fact, we can approximate the total additional effect by

$$
\begin{aligned}
& d u+d b=-\frac{1}{\Delta}\left\{(t-1)\left[\mu_{2} \bar{\varepsilon}_{1}^{*}+\left(1-\mu_{1}^{*}\right) \bar{\varepsilon}_{2}\right]+\left(1-\mu_{1}^{*}-\mu_{2}\right)\right\} \\
& d u^{*}-d b=\frac{1}{\Delta}\left\{\left(t^{*}-1\right)\left[\left(1-\mu_{2}\right) \bar{\varepsilon}_{1}^{*}+\mu_{1}^{*} \bar{\varepsilon}_{2}\right]+\left(1-\mu_{1}^{*}-\mu_{2}\right)\right\} .
\end{aligned}
$$

The higher the rate of tariffs $t$ (resp. $t^{*}$ ), the more likely is the right-hand side of equation (31) (resp. (32)) to assume a positive value unless parameters $m_{2}$ and $\bar{\eta}_{2}$ (resp. $m_{1}^{*}$ and $\dot{\eta}_{1}^{*}$ ) are thereby significantly affected. Thus, we may conclude that the presence of tariffs lends a strong supporting hand to the orthodox presumption of "additional burden" under the normal circumstances. Let us turn to the examination of anomalous situations in which some commodities are inferior in consumption.

\section{A GEOMETRIC ANALYSIS OF ANOMALIES}

To simplify further analyses, let us assume in this section that $\mu_{1}^{*}+\mu_{2}=1$, or that the terms of trade is not affected by a transfer. This reduces equations (29) and (30) to

$$
\begin{aligned}
& d u=-d b-(t-1) \mu_{2} d b \\
& d u^{*}=d b+\left(t^{*}-1\right) \mu_{1} d b
\end{aligned}
$$


In each equation, the first term on the right-hand side represents the primary effect of a transfer on real income, and the second term the additional effect, or the change in tariff revenue. In the absence of price variations, a change in real income is synonymous with a change in nominal income, and the additional effect is equivalent to the "tertiary" effect. Here we assume that the rates of tariffs are positive, or $t>1$ and $t^{*}>1$. We drop the case of negative tariffs from our consideration since we can handle it easily in a similar fashion. From Figure 1-i, notice

$$
\begin{aligned}
& \operatorname{sign} \mu_{2}=\operatorname{sign} m_{2} \text { and } \mu_{2}>-\frac{1}{t-1} \quad \text { if } m_{2}<\frac{t}{t-1} ; \\
& \operatorname{sign} \mu_{1}^{*}=\operatorname{sign} m_{1}^{*} \text { and } \mu_{1}^{*}>-\frac{1}{t^{*}-1} \quad \text { if } m_{1}^{*}<\frac{t^{*}}{t^{*}-1} .
\end{aligned}
$$

In view of equations (33) and (34), this enables us to state

Proposition 3. Suppose that a transfer from the home to the foreign country does not affect the terms of trade under positive tariffs. (i) Let $m_{2}<t /(t-1)$. Then, if the home country's importable is normal, or $m_{2}>0$, there will be a decrease in the home tariff revenue. If $m_{2}<0$, there will be an increase in the home tariff revenue, but the increment will never exceed the value of transfer. (ii) Let $m_{1}^{*}<t^{*} /\left(t^{*}-1\right)$. Then, if the foreign country's importable is normal, or $m_{1}^{*}<0$, there will be an increase in the foreign tariff revenue. If $m_{1}^{*}>0$, there will be a decrease in the foreign tariff revenue, but the decrement will never outweigh the value of transfer.

For given values of $m_{1}^{*}$ and $m_{2}$, the relative magnitude of changes in tariff revenue depends on the rate of tariffs. For $m_{2}>1 / 2$, the reduction of home tariff revenue overshadows the value of transfer if $\tau>1 /\left(2 m_{2}-1\right)$. Likewise,

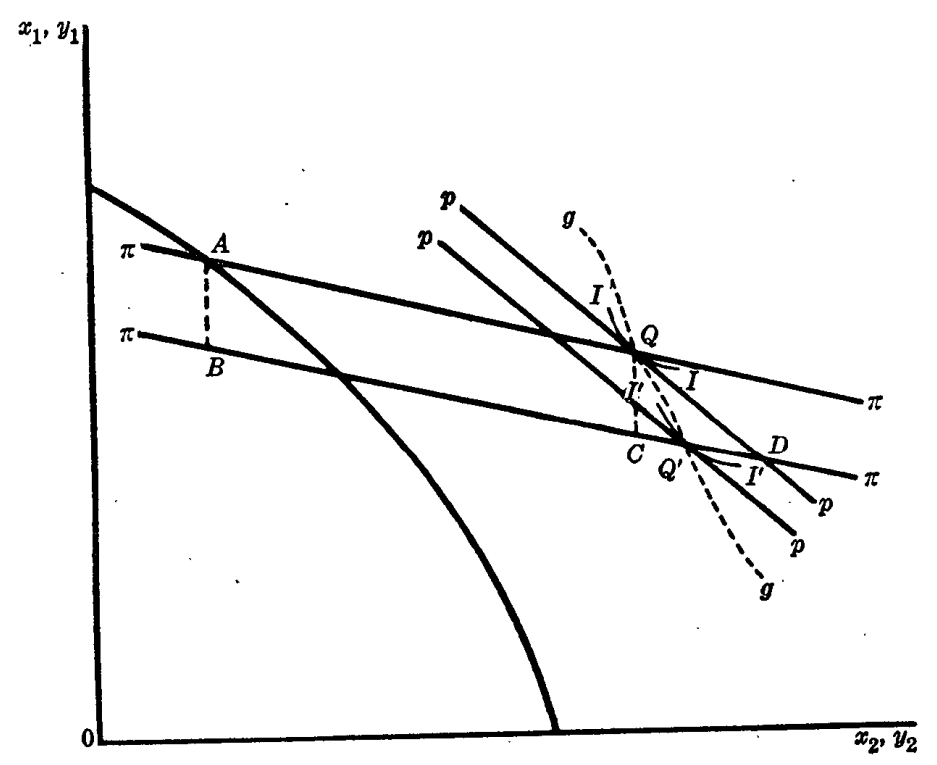

Fig. 2-i. 
for $m_{1}^{*}>1 / 2$, the addition to the foreign country's tariff revenue is greater than the value of transfer if $\tau^{*}>1 /\left(2 m_{1}^{*}-1\right)$.

The common sense of this result is illustrated in Fig. 2-i for the home country (the transferor). It shows the home country's production possibilities schedule and the social indifference curves. Suppose that the equilibrium production is at $A$, given the rate of tariffs and the terms of trade indicated by the slope of the $\pi-\pi$ line. The indifference curve II is tangential at the initial consumption equilibrium point $Q$ to the $p-p$ line whose slope represents the domestic relative price. Consider the impact of a transfer payment $A B$ in terms of commodity 1 under the constant terms of trade. The vertical shift from $Q$ to $C$ on the lower $\pi-\pi$ line may be considered as the primary loss of home real income before there is any change in the import volume, and tehrefore in the tariff revenue. The new consumption equilibrium must, however, be at a point on the lower $\pi-\pi$ line where an indifference curve has the slope of the $p-p$ line. The dotted, downwardsloping curve gg is drawn in to represent the Engel curve for the constant domestic relative price on the assumption that commodity 2 is inferior in the home country, or $m_{2}<0$. Hence, the new consumption equilibrium is at $Q^{\prime}$ to the right of $C$ where the Engel curve cuts the lower $\pi-\pi$ line. The shift from $C$ to $Q^{\prime}$ clearly involves an increase in the import volume and therefore in the tariff revenue. The indifference curve $I^{\prime} I^{\prime}$ through $Q^{\prime}$ is indeed higher than the one through $C$ (not drawn). Note that it is impossible for the Engel curve to have an intersection with the lower $\pi-\pi$ line to the right of $D$ where the upper $p-p$ line cuts the lower $\pi-\pi$ line. That would simply contradict the assumption of inferiority. On the other hand, if commodity 2 had been assumed to be superior in the home country, we would have found the new consumption equilibrium to the left of $C$ under the condition of Proposition 3.

So far the result is merely reasonable. Let us consider the possibility that the paying country somehow ends up with an extra real income, or the receiving country gets impoverished as a result of transfer. No such anomalies seem to obtain under usual circumstances. But Fig. 1-i indicates

$$
\begin{aligned}
& \mu_{2}<-\frac{1}{t-1} \quad \text { if } \quad m_{2}>\frac{t}{t-1} \\
& \mu_{1}^{*}<-\frac{1}{t^{*}-1} \quad \text { if } \quad m_{1}^{*}>\frac{t^{*}}{t^{*}-1} .
\end{aligned}
$$

This, along with (33) and (34), leads to

Proposition 4. Suppose that a transfer from the home to the foreign country does not affect the terms of trade under positive tariffs. (i) Let $m_{2}>t(\mid t-1)$. Then, the home country will increase its tariff revenue by the amount greater than the value of transfer. (ii) Let $m_{1}^{*}>t /\left(t^{*}-1\right)$. Then, the foreign country will decrease its tariff revenue by the amount greater than the value of transfer.

Note that (i) and (ii) cannot hold at the same time because of the restriction $\mu_{1}^{*}+\mu_{2}=1$. 


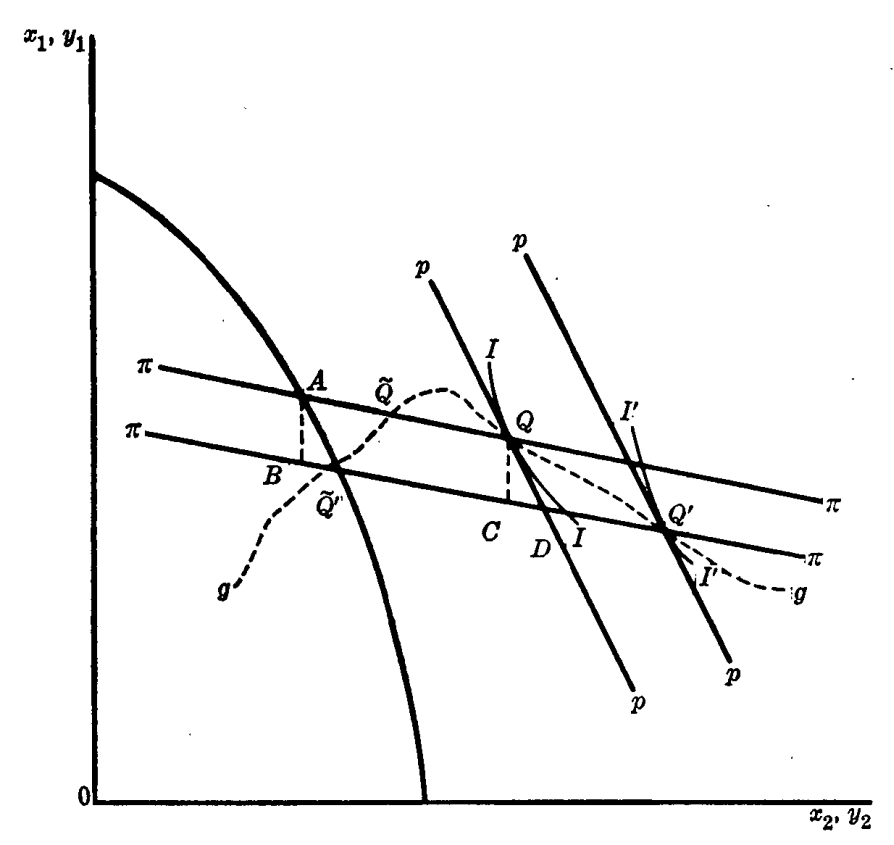

Fig. 2-ii.

Since $t>1$ and $t^{*}>1$, the condition for this paradox invovles the strong inferiority of each country's exportable commodity. It is shown, again for the home country, by Fig. 2-ii, which is basically similar to Fig. 2-i. Here, the Engel curve $g g$ is given a flatter slope than the $p-p$ line in the neighborhood of the initial consumption equilibrium. This must be so under the condition $m_{2}>t /(t-1)$ because

$$
-\frac{d x_{1}}{d x_{2}}=-p\left(\frac{m_{1}}{m_{2}}\right)=-p\left(\frac{1-m_{2}}{m_{2}}\right)<\frac{1}{t} p .
$$

As before, the vertical shift from $Q$ to $C$ represents the primary loss of home real income after transfer. With its slope as such, the Engel curve cuts the lower $\pi-\pi$ line at $Q^{\prime}$ to the right of $D$. This of course shows the existence of a new consumption equilibrium with a greater real income than before. A vigorous expansion of the home country's imports is, however, essential for this equilibrium to be realized.

Some may question the attainability of such an equilibrium. They will argue that if $m_{2}>t /(t-1)$, the consumption equilibrium cannot be sustainable. ${ }^{6}$ Consider a random departure of the country's income from the equilibrium position under a constant terms of trade. As described above, this will set forth a tariff-import multiplier process. But this time, the process will be explosive rather than convergent as in every round the change of the country's import volume tends to overwhelm that of the previous round. In this connection, note that as home real income diminishes, the Engel curve must eventually approach

6 See, for example, Kemp (1964), p. 37. A modified viewpoint is, however, found in Kemp (1969), p. 66. 
the origin. As shown in Fig. 2-ii, the curve must at some point turn round and cut the $\pi-\pi$ lines once more as at $\widetilde{Q}$ and $\widetilde{Q}^{\prime}$. This is the well-known phenomenom of multiple equilibria under tariffs. According to the above viewpoint, it is $\widetilde{Q}$ or $\widetilde{Q}^{\prime}$ that represents the lasting choice of the people, but evidently there can be no paradox between $\widetilde{Q}$ and $\widetilde{Q}^{\prime}$. This suspicion may seem to be reasonable at first, but turns out to be much less convincing in reflection. For after all, the real income position of $\widetilde{Q}$ or $\widetilde{Q}^{\prime}$ is absolutely inferior to $Q$ or $Q^{\prime}$. This means that at $\widetilde{Q}$ or $\widetilde{Q}^{\prime}$, the people are failing to achieve the maximum well-being for the given terms of trade, tariffs, and the consequent budget constraint. There is in fact no reason to justify such a myopic behavior on the part of the people except for ignorance and irratioanlity. Therefore, we may simply disregard a choice such as $\widetilde{Q}$ or $\widetilde{Q}^{\prime}$ in favour of $Q$ or $Q^{\prime}$. In this instance, the real question is whether the international market can be stable in the usual sense under the condition of Proposition 4. From the definition of $\varepsilon_{2}, m_{2}>t /(t-1)$ implies $\varepsilon_{2}<0$. Hence, the stability condition requires $\varepsilon_{1}^{*}>1-\varepsilon_{2}>1$, or that the foreign offer curve be sufficiently elastic. Since, under the restriction $\mu_{1}^{*}+\mu_{2}=1$, there is no upper limit for the possible values of $\varepsilon_{1}^{*}$, we should be able to provide an example of a stable equilibrium appropriate for the case under consideration.

In this section we have taken much advantage of the simplifying assumption that $\mu_{1}^{*}+\mu_{2}=1$. But the gist of our discussion will not be destroyed in the general case of variable terms of trade.

\section{NOTES ON TIED TRANSFER}

It is thus far taken for granted that a transfer from the home to the foreign country is completely untied. In other words, the latter is assumed to dispose of the transfer in the form of lump-sum subsidies without any restriction. This assumption is common in the standard discussions of the transfer problem, and serves to isolate the effect of pure income transfer. In reality, however, genuine gifts are rare, and we find transfers tied in various ways. Consider for example international economic aids which are tied by source or end-use via specification of commodities or countries. Despite the intrinsic interest of the issue, the analysis of tied transfer has been largely neglected in the literature on the transfer problem. In this section, we shall make a small step to fill in this gap.

Generally speaking, a transfer is tied if accompanied by a contractual requirement that the recipient country spends the transfered purhcasing power for promoting its import of specified commodites from specified countries. In our twocountry, two-commodity model, however, there is evidently no degree of feedom of choice of specified commodities or countries. We can, however, think of several distinct ways of tying a transfer so as to expand the recipient country's imports. Let us confine ourselves to the following two typical cases. First, the home country grants an income transfer to the foreign country only on the condition that the latter agrees to increase its import value up to the amount of the transfer. 
Secondly, the foreign country agrees to employ the fund to subsidize its imports. For simplicity, we assume that there were no tariffs before the transfer, or $t=t^{*}=1$.

Case (i) The foreign country is supposed to subsidize its import to achieve the requirement

$$
d b=d\left(p_{1} e_{1}^{*}\right)=p_{1} e_{1}^{*} \hat{e}_{1}^{*}
$$

Since we have agreed to regard $p_{1}$ as a constant, the right-hand side of (35) represents the value of the foreign import increment in the post-transfer equilibrium. Substitute (35) into (24), and let $\hat{t}=0$ to get

$$
\hat{\pi}=\frac{1}{\Delta}\left[\bar{\eta}_{1}^{*} \hat{t}^{*}+\left(1-m_{1}^{*}-m_{2}\right) \hat{e}_{1}^{*}\right] \text {. }
$$

From (22) and (35), we find

$$
\bar{\eta}_{1}^{*} \hat{t}^{*}=-\left(1-m_{1}^{*}\right) \hat{e}_{1}^{*}+\eta_{1}^{*} \hat{\pi} .
$$

Substituting this back into (36) and collecting terms, we obtain

$$
\hat{\pi}=-\frac{m_{2}}{\eta_{2}-1} \hat{e}_{1}^{*}
$$

Since $\hat{e}_{1}^{*}=d b /\left(p_{1}^{*} e_{1}^{*}\right)>0$, the terms of trade improves for the home country provided that commodity 2 is normal, and the home offer curve is elastic. The economic interpretation of this result is fairly starightforward. In the absence of the terms of trade variation, the value of the home country's imports will diminish by $m_{2} d b$, while that of the foreign imports expands by $d b$ because of the requirement (35). Thus, the net surplus in the home country's balance of payments is $\left(m_{2} d b+d b\right)-d b=m_{2} d b$. On the other hand, we know from the analysis of the offer curves that the value of the home country's imports increases as the terms of trade improves if and only if the home offer curve is elastic. Since the value of the foreign imports is frozen, the value of home imports must increase to wipe out the surplus $m_{2} d b$. This will give rise to the terms of trade improvement if and only if $\tilde{\eta}_{2}>1$.

The effect of the present case on the foreign real income can be readily obtained from (20), (35) and (37):

$$
d u^{*}=\frac{\bar{\eta}_{2}-1}{\eta_{2}-1} d b
$$

Clearly, the foreign real income gain is less than the face value of the transfer if the terms of trade moves against the foreign country. As no tariffs exist intially, the change in the home real income is simply given by $d u=-d u^{*}$. In summary, we may state

PROPOSITION 5. Suppose that the foreign country agrees to increase its import value up to the amount of a transfer given by the home country. Suppose also the superiority of the home country's importable, or $m_{2}>0$. Then, the terms of trade will improve for the home country as a result of transfer if and only if the home offer 
curve is elastic. If there are no tariffs initially, the home country (transferor) will derive a real income gain, and the foreign country (transferee) will invite a real income loss from such an arrangement when condition

$$
\eta_{2}>1>\bar{\eta}_{2}
$$

is satisfied.

Case (ii) Now, the foreign country is supposed to exhaust the transfered fund in subsidizing its imports, viz.

$$
d b=-p_{1} e_{1}^{*} \cdot d \tau^{*}=-p_{1} e_{1}^{*} \cdot \hat{t}^{*} .
$$

With $\hat{t}^{*}$ being negative, the right-hand side of this equation shows the value of the foreign subsidies in the postransfer equilibrium $t^{*}=1$. As before, suppose $\hat{t}=0$. The substitution of (40) into (24) yields

$$
\hat{\pi}=-\frac{1}{p_{2}^{*} e_{2} \Delta}\left(\eta_{1}^{*}+m_{2}-1\right) d b .
$$

Or the terms of trade improves for the home country if and only if the condition

$$
\eta_{1}^{*}>1-m_{2}
$$

is satisfied. Note that this is none but the familiar Metzler condition for protective tariffs. Upon a little reflection, however, the result obtained is not at all surprising. The present form of tied transfer would be equivalent in its impact effect to the home country's subsidizing exports if we reinterpret the terms of trade as the domestic relative price in the home country. But by Lerner's symmetry theorem, export subsidies are equivalent to import subsidies or negative tariffs.

We can calculate the change in the foreign real income from (20) and (41) as

$$
d u^{*}=\frac{1}{\Delta} \bar{\eta}_{2} \cdot d b
$$

The change in the home real income is again given by $d u=-d u^{*}$. One can easily see that this is identical to the real income effect of the home export subsidies. After the transfer, the home country will be made definitely worse-off, and the foreign country definitely better-off, but not so much as in the case of untied pure transfer.

This simple conclusion suggests yet another equivalence relationship. Suppose that, in addition to the present scheme of tied transfer, the home country taxes imports so as to finance the transfer payment. Then, we obtain

$$
d b=p_{1} e_{1}^{*} \cdot \hat{t}
$$

instead of $\hat{t}=0$. From (24), (40) and (44),

$$
\hat{\pi}=-\frac{1}{p_{1} e_{1}^{*}} d b \text {. }
$$

The terms of trade will certainly improve for the home country, and yet there will be no ultimate real income effect. To sum up, we have

Proposition 6. Suppose no tariffs exist initially. A transfer from the home to 
the foreign country can be made equivalent in its real income effect to the home country's import subsidies by the agreement that the foreign country uses the transferred sum solely to subsidize imports. Consequently, a transfer tied in this way will have weaker effects on real incomes than the untied transfer of the same face value. Furthermore, consider a simultaneous introduction of import subsidies in the foreign country and import taxes in the home country such that the subsidy expenditure is of the same value as the tariff revenue. This will be equivalent in its real income effect to a transfer from the foreign to the home country amounting to the common value of the subsidy expenditure and the tariff revenue.

\section{CONCLUDING REMARKS}

We have investigated the effect of an international income transfer in some detail in the context of a simple two-country, two-commodity model of trade with tariffs. The orthodox presumption about the terms of trade movement has been given a favorable judgement in the presence of positive tariffs. This finding confirms the conclusion obtained by Samuelson $(1952,1954)$ with some gain in clarity and insight becaue of the explicit introduction of the concept of real income change. Furthermore, we have been able to bring into strong relief the tertiary effect of transfer in the form of tariff revenue variation. Under normal conditions, the paying country suffers from a reduction in tariff revenue, while the receiving country enjoys an increase in tariff revenue. Thus, when there are tariffs, the former is likely to experience extra losses, and the latter extra gains as a result of transfer on double accounts, i.e., the terms of trade change and tariff revenue variation. To the best of our knowledge, the significance of the tertiary effect of transfer is largely ignored in the literature despite the universal presence of tariffs in the real world. In this connection, it should be noted that tariffs for revenue pruposes are still popular among some developing countries because of the savings made possible in administrative costs of tax collection ${ }^{7}$. The changes in tariff revenue consequent upon a transfer should not be a matter of negligible concern for such countries.

The transfer problem takes on special interest in the tariff-ridden world because of the possibility that the paying country becomes better-off and the receiving country worse-off as a result of transfer. We have considered this rather improbable outcome in some length primarily as a theoretical curio. This point will be, however, of little practical importance save for the case of tied transfer, which attracts one's attention because of its relevance in reality rather than its value in theory. As a matter of fact, it is a common presumption that a tied transfer will be less costly to the transferor and less beneficial to the transferee than the untied transfer of the same face value. One can certainly go further and demostrate that it is almost probable for the giver to benefit and the recipient to

\footnotetext{
7 See, for example, Bangs (1968), pp. 121-126, and pp. 130-133.
} 
suffer from a certain type of arrangement of tied transfer. This is what we have tried to bring home in the last section by way of application of the model of tariffs and transfer.

\section{Keio University}

\section{REFERENCES}

[1] Bangs, R. B., 1968, Financing Economic Development: Fiscal Policy for Emerging Country. The University of Chicago Press: Chicago.

[2] Johnson, H. G., 1955, "The Transfer Problem: A Note on Criteria for Changes in the Terms of Trade," Economica, Vol. 22 (May), 113-121.

[ 3 ] Jones, R. W., 1969, "Tariffs and Trade in General Equilibrium: Comment," American Economic Review, Vol. 59 (June), 418-424.

[4] Kemp, M. C., 1964, The Pure Theory of International Trade, Englewood Cliffs, N. J.: Prentice-Hall.

[5] 1 1969, The Pure Theory of International Trade and Investment, Englewood Cliffs, N. J.: Prentice-Hall.

[ 6 ] Keynes, J. M., 1929, “The German Transfer Problem,” Economic Journal, Vol. 39 (March), $1-7$.

[ 8 ] Ohlin, B., 1929, "The Reparation Problem: A Discussion," Economic Jorunal, Vol. 39 (June), 172-178.

[ 8] Samuelson, P. A., 1952, "The Transfer Problem and Transport Costs: The Terms of Trade when Impediments are Absent," Economic Journal, Vol. 62 (June), 278-304.

[9] - 1954, "The Transfer Problem and Transport Costs, II: Analysis of Effects of Trade Impediments," Economic Journal, Vol. 64 (June), 264-289. 